FACULDADE DE MEDICINA DA UNIVERSIDADE DE S̃̃O PAULO - $2 .^{a}$ CADEIRA DE CLINICA CIRURGICA - Prof. B. MONTENEGRO

\title{
SÔBRE UM CASO DE SARCOMA DO EPIDIDIMO
}

DR. PLINIO BOVE
DR. ABDUHADER ADURA

Assistentes voluntários

Iniciaremos o presente trabalho relatando a observação e em seguida teceremos alguns comentários em torno do caso.

\section{OBSERVAÇÃO}

J. M. S., com 16 anos de idade, solteiro, branco, brasileiro, comerciário, residente na Capital. Entrado em 8-11-40. Alta em 18-11-40.

Queixa e anuração: Tumor na região ínguino-escrotal direica há cinco meses.

H. P. M. A.: Há cinco meses notou, ocasionalmente, a exis tência na parte média da bolsa escrotal direita de um ligeiro intumescimento com o volume aproximado ao de uma avelã, duro, indolor à palpação, fazendo corpo com o testículo ou epidídimo e não aderente aos tecidos circunvisinhos.

Notou ao mesmo tempo que a referida região se apresentava ligeiramente hiperemiada e hipertérmica, sem .que isso 'o incomodasse. Não tinha febre, nem tosse.

Procurou, então, um médico que the prescreveu injeções, cujo nome desconhece, não tendo sentido com o uso das mesmas nenhuma melhora.

Com o decorrer do tempo a tumoração foi crescendo igualmente em todos os sentidos, tendo por fim se alongado para cima na direção do cordão espermático.

A não ser o aumento de volume do tumor, nada mais notou durante os quatro primeiros meses de moléstia.

Nesse último mês apareceram-lhe dores poụco intensas ao nivel do tumor', mas que se manifestavam somente por ocasião de movimentos bruscos efetuados pelo paciente. 
Isto levou-o a procurar outro clínico que fez um exame de sangue de resultado negativo. Durante todo o evoluir da moléstia não emagreceu. A conselho de médico procurou a Santa Casa, tendo dado entrada em nossa enfermaria (4. ${ }^{\mathrm{a}}$ Cirurgia de Homens) no dia 8-11-940.

Antccedentes Pessoais: Negà moléstias venéreo-sifilíticas e afecções pulmonares.

Anteccdentes familiarcs: Nada digno de nota. Desconhece a existência de caso semelhante em membros da família. nota.

Intcrrogatório sobre os diferentes aparelhos: Nada digno de

Exame físico geral: Indivíduo normolíneo, "facies" sem característico, aparentando a idade que afirma ter; pele quente e húmida, sem edema e sem circulação colateral; pêlos bem desenvolvidos e distribuidos de acordo com o sexo. Panículo adiposo regularmente desenvolvido. Sistema muscular e ósseo sem caracteres anormais. Sistema ganglionar nada digno de nota. Marcha sem anormalidades.

Extame físico especial: Cabeça, Olhos, Bôca e Pescoço: nada digno de nota.

Torax: As inspecções estática e dinâmica nada revélam.

Coração: A inspecção e palpação da área precordial nada digno de nota; o mesmo quanto à ausculta dos focos.

Artérias: Pulso: 60. P Mx: 130. P Mn: 70.

Abdomen: A inspecção, percussão e palpação nada revelam.

Sistema neuro-muscular: nada digno de nota.

\section{EXAME LOCAL}

Pela inspecção, doente em decúbito dórsal, nota-se um tumor com o tamanho de uma pera, na região ínguino-escrotal direita.

A pele do escroto mostra-se tensa e ligeiramente hiperemiada. O tumor ocupa a totalidade da bolsá escrotal direita, tendo a base voltada para baixo e o ápice fazendo corpo com o cordão espermático, atinge o nivel do orifício inguinal superficial.

À palpação verifica-se que é de superfície lisa e regular; de consistência dura e elástica; ligeiramente doloroso. A pele não é aderente ao tumor. $\mathrm{Na}$ sua região anterior há uma pequẹa área que apresenta nítida flutuação. Não conseguimos pela palpação identificar no seio da tumoração nem testículo, nem epidídimo é nem os elementos do cordão. O tumor é perfeitamente delimitado, não apresentando modificação quer na sua forma, quer no seu volume, pelas variações da pressão intra-abdominal ou pelas alterações de posição do
paciente ou ainda por manobras de taxis.

A percussão revela massicês.

A prova da transiluminação revelou opacidade da área tumoral. 

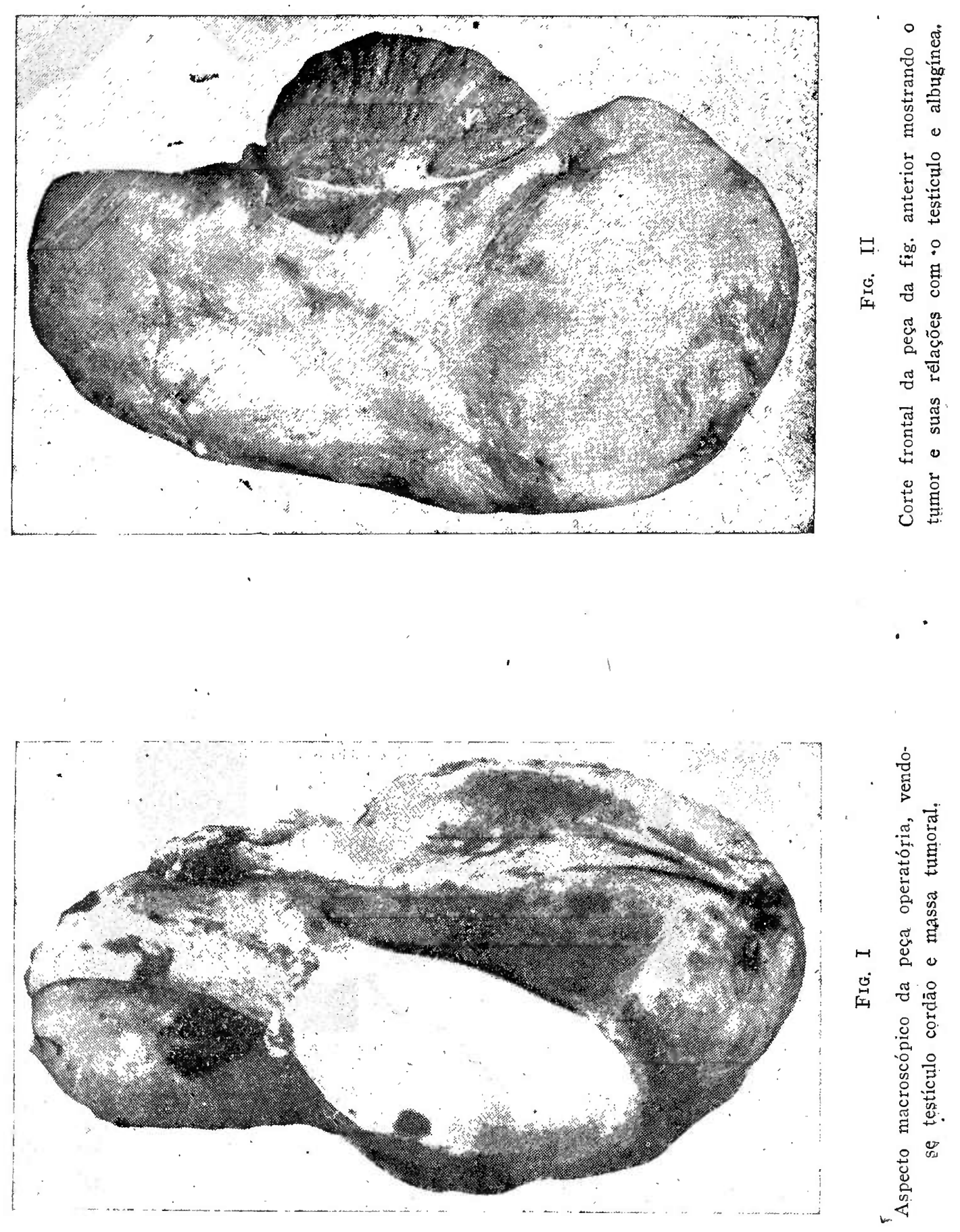
Testículo, epiclídimo, cordão espermático esquerdo, como tambem os sens invólucros mostraram-se sem caracteres anormais.

Exames subsidiários: Exame de urina - tipo I: Negativo.

Reação de Ascheim-Zondek: Negativa .

Reação de N'assermann: Negativa.

Exames radiológicos:

a) Torax: Áreas pulmonares de transparência normal. Área cardíaca sem caracteres anormais.

b) Coluna vertebral e bacia: nada de anormal.

c) Aparelho urinário: Pela radiografia simples nota-se ausência de sombras calculosas. As sombras renais de tamanho e topogra-

- fia normais. A urografia excretora revela eliminação do contraste em tempo normal. Cálices, bacinetes, ureteres de conformação, dimensões e dinanismo dentro da normalidade. Bexiga de dimensão e conformação tambem normais.

Diagnóstico clínico: Tumor intra-escrotal direito.

Não sendo possivel clinicamente estabelecer-se a natureza e séde precisa da neoplasia, e como a maioria dos tumores dessa região é representada por neopalsma malignos do testículo, resolvemos intervir cirurgicamente.

Ficha Cirúrgica: Operador: Dr. Plínio Bove. Auxiliar: Dr. Abduhader Adura. Dia da operação: 11-11-40.

Anestesia: Raquipercainisação associado ao cardiazol-efedrina.

Descrição: Incisão de oito centímetros aproximadamente estendendo-se do terço médio da região inginal até a porção súpero-lateral da bolsa escrotal, lado direito.

Seccionam-se pele e tecido celular subcutâneo, faz-se a respectiva hemostasia. Secção da aponevirose do grande oblíquo; libertação do cordão espermático até a vaginal que é aberta.

O testículo, macroscopicamente, apresenta-se sem lesões. A vaginal e o cordão espermático, idem. O epidídimo, situado pósterointernamente em relação ao testículo, mostra-se muito aumentado de volume, piriforme, de consistência dura e elástica. Secção do cordão espermático após prévia ligadura em massa.

Dissecção do tumor, coto do cordão e testículo em um só bloco com extirpação subsequente. Reconstituição dos planos cutâneoaponevróticos. Drenagem com drêno de borracha. Penso sêco.

Diagnóstico cirúrgico: Tumor do epidídimo.

Evolução imediata: O período posoperatório decorreu normalmente, tendo o paciente recebido alta curado no dia 17-11-40.

Diagnóstico histopatológico: Sarcoma parvi-fuso-celular do epidídimo. (Prof. Carmo Lordy).

Evolução mediata: Recomendamos aplicações de radioterapia profunda nas regiões operada e abdominal visando com essa terapêutica, principalmente, os gânglios e cadeia linfática retroperitoneniais. 
Aconselhamos ao paciente que voltasse periodicamente ao serviço afim de submeter-se a exames clínico e radiológico.

Durante os três primeiros meses após a operação nada ocorreu de anormal; entretanto, passado esse tempo o doente voltou a nossa procura queixando-se de dores na região axilar direita.

O exame radiográfico dos pulmões feito nesse momento revelou uma sombra que suspeitamos tratar-se de u'a metastase pulmonar. Enviamos o enfermo novaménte ao radioterapeuta que fez aplicações de R.X. sobre a região acima descriminada.

Em seguida acompanhamos a evolução da metástase, semanalmente, com radiografias, sem que até hoje aparecessem sensiveis modificaçôes na sombra pulmonar.

O doente continua sendo observado, semanalmente, não podendo nós aquilatar completamente a evolução tardia do caso.

Faremos a seguir alguns comentários a propósito das neoplasias do epidídimo analisando:

a) Classificação dos tumores do epidídimo.

b) Frequência - Frequência dos sarcomas.

c). Sintonratologia, diagnóstico e tratamento.

Os tumores sólidos primários do epidídimo classificam-se de acordo com Hinman:

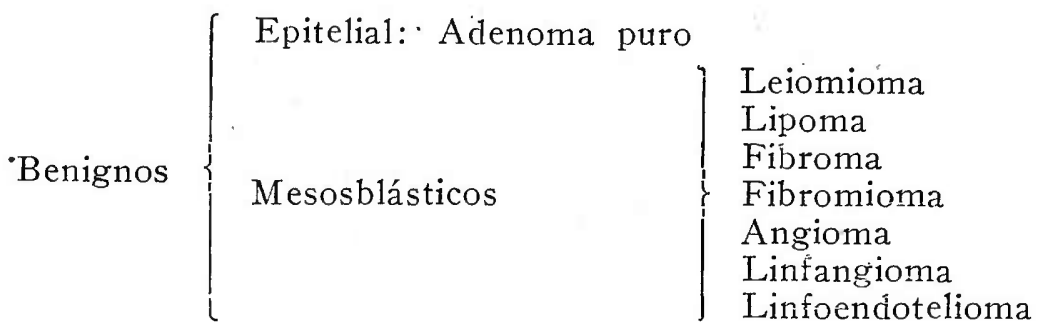

Malignos $\left\{\begin{array}{l}\text { Epitelial: Carcinoma } \\ \text { Mesoblásticos: Sarcomas } \\ \begin{array}{l}\text { Linfosarcoma } \\ \text { Condrosárcoma } \\ \text { Melanosarcoma } \\ \text { Sarcoma fuso-celular }\end{array}\end{array}\right.$

Esta classificação baseia-se no estudo de 16 casos de tumores benignos e de 28 de tumores malignos coligidos da literatura mundial por Hinman e Gibson, por Rubaschow e Scholl. Não pode ser considerada como definitiva pois como pondera o primeiro desses autores muitos dos casos citados como neoplasias do epidídimo se ori- 
ginam dos tecidos circunvisinhos, mais particularmente da "rete testis". Afirma o mesmo pesquizador que neoplasias oriundas da "rete testis" podem invadir nas primeiras fases mais o epidídimo que o testículo de tal maneira a produzir um quadro clínico de inflamação ou tumor daquele. órgão.

EWING, citado por HINMAN, escreve que a origem na "rete testis" e a ocasional invasão, principalmente, do epidídimo reforça a idéia de que carcinomas de células redondas, erradamente descritos como sarcomas devem ser considerados como teratomas unilaterais e não seminomas como quer Chevassu.

\section{FREQUENCIA}

Hinman (1937) reuniu da literatura mundial 44 casos de neoplasias do epidídimo, sendo 16 tumores benignos e 28 malignos.

Dos 16 benignos, 1 foi descrito por SAKAGUCHI como adenoma puro; os 15 restantes representam para HiNMAN "um grupo duvidoso muito provavelmente originado dos tecidos circunvisinhos, tais como tunicas e anexos".

Dos 28 casos de neoplasias malignas existem 8 carcinomas e 20 sarcomas. Os carcinomas são representados pelas seguintes variedades: carcinoma primitivo, adenocarcinoma, e epitelioma escamoso. Os sarcomas encontrados são: linfosarcoma, condrosarcoma, melanosarcoma e sarcoma' fuso-celular.

Hinman escreve que muitas vezes é impossivel determinar quando esses tumores se originam no canal deferente ou no epidídimo.

Frequência dos sarcomas: Pelo exposto vê-se que além da pobreza de casos na literatura mundial, apenas 20 , muitos destes ainda comportam dúvidas quanto à origem epididimária.

Entre nós não existe relatado caso de sarcoma do epidídimo. Esta afirmativa baseia-se na análise cuidadosa das seguintes fontes:

1. $\left.{ }^{\circ}\right)$ Índice catálogo médico paulista.

2..$^{\circ}$ Relatórios de biópsias.

3. $\left.{ }^{\circ}\right)$ Relatórios de necrópsias.

$1^{\circ} .^{\circ}$ Indice catálogo médico paulista: Compulsando o índice catálogo médico paulista (1860-1936), trabalho utilíssimo que o Dr. Jorge de Andrade Maia, bibliotecário da Faculdade de Medicina, conseguiu organisar, não encontramos mencionado nenhum caso de sarcoma do epidídimo.

Segundo apuramos nada há referente ao assunto. na literatura médica paulista, entre os anos de 1937 e 1939.

Assim sendo, podemos escrever que desde 1860 até 1939, em S. Paulo, não foi escrito nenhum trabalho a respeito de tal tumor maligno. 


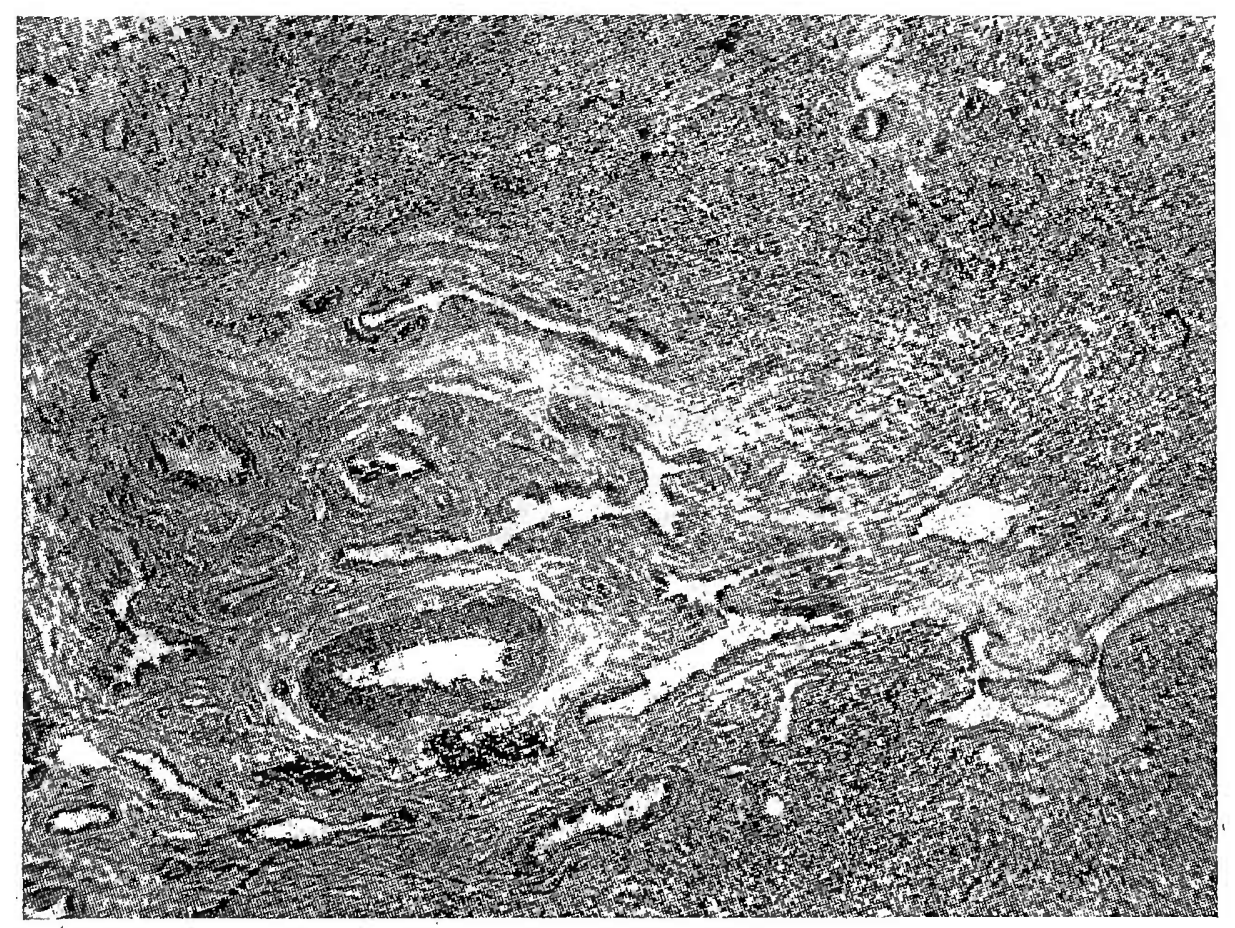

FIG. III

Sarcoma parvi-fuso-celular do epidídimo. (Prof. Carmo Lordy).

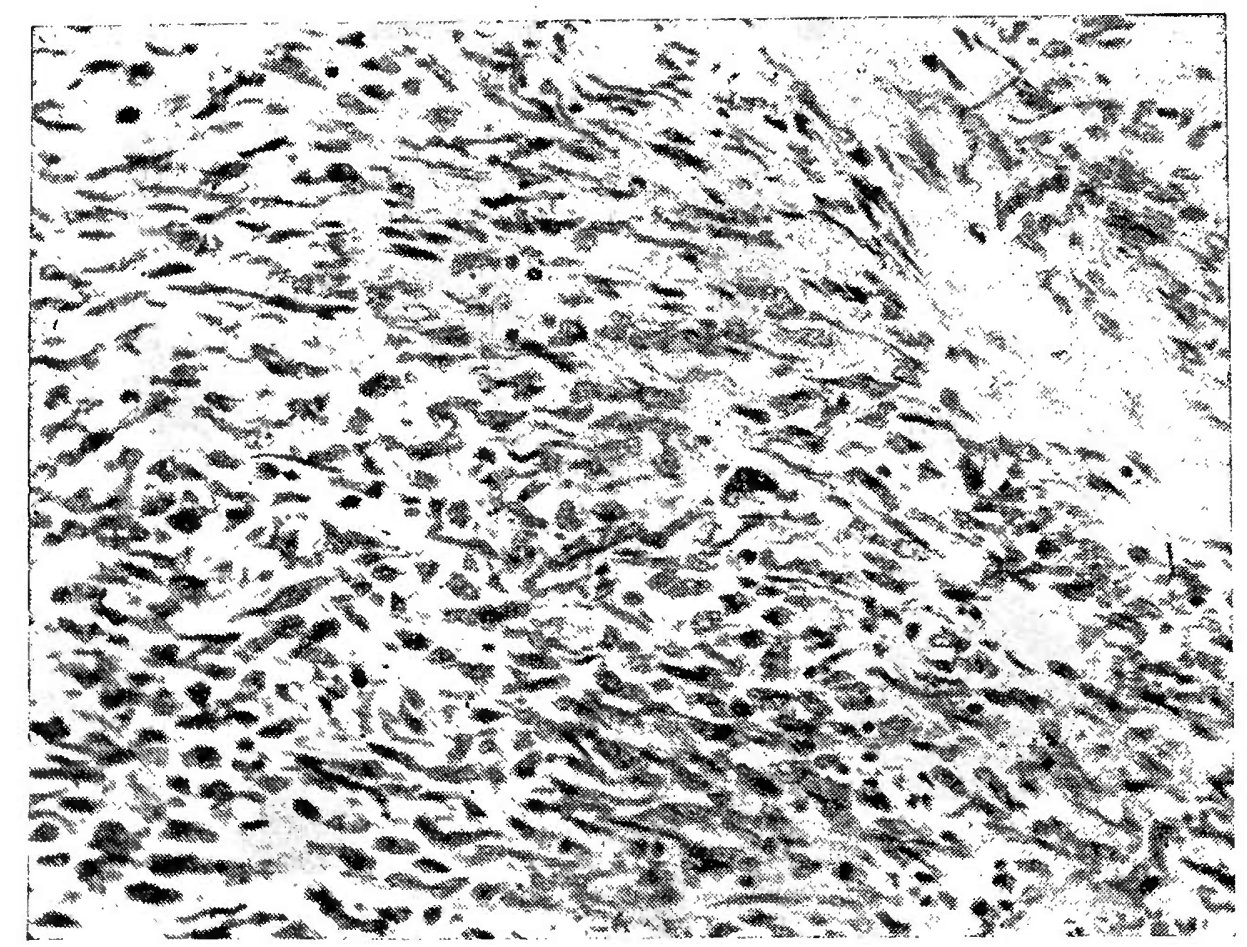

FIG. IV

Sarcoma parvi-fuso-celular do epidídimo.

(Prof. Carmo Lordy). 
$20^{\circ)}$ Relatórios de biópsias: Os relatórios anátomo-patológicos (le biojpsias comecaram a ser feitos na Faculdade de Medicina a partir de 1921. Analisando a tese de autoria do Dr. Benedito Streib Fernancles, intitulada "A incidência e distrilunição de tumores recebidos no Instituto de Anatomia Patológica de São Paulo" notamos que não está assinalado nenhum caso de sarcoma do epidíclimo.

Nada encontramos tambem examinando todos os relatórios de 1923 até 30 de Novembro de 1940 (Foram vistos tres relatórios com diagnóstico de sarcoma; o órgão nâo era especificado).

Concluindo podemos afirmar que num total de 9.750 biópsias (de 1921 até 30 de Noveml)ro de 1940) não se acha consignado nenhum caso de sarcoma do epidídimo.

3. $\left.{ }^{\circ}\right)$ Relatórios de necrópsias: E' aproximadamente de 15.626 o total de necrópsias realizadas no Departamento de Anatomia Patológica da Faculdade de Medicina de São Paulo. Benedito Streib Fer. nandes analisando 679 relatórios (1916-1922) não cita nenhum caso de sarcoma do epidídimo.

Nós auxiliados pelo acadêmico Renato Alves Godoy, compulsando 13.400 relatórios (1923 - 16 de Novembro de 1940) nada encontramos a propósito de semelhante neoplasia. Não conseguimos examinar 1.547 relatórios, pois na sua maioria foram entregues af; serviço de encadernação.

\section{SINTOMATOLOGIA - DIAGNÓSTICO - TRATAMENTO}

A sintomatologia do sarcoma do epidímo nada apresenta de particular que o diferencie de qualquer outra tumoração intra-escrotal. Diante de um tumor intra-escrotal é necessário em primeiro lugar excluir a possibilidade de uma hidrocele ou de um cisto do epidídimo, o que se consegue pela transiluminação.

Verificada a opacidade da bolsa restam as seguintes eventualidades: tumor, lesões inflamatórias crônicas específicas ou inespecíficas, e hematocéle.

Geralmente não é dificil estabelecer a diferença entre um tumor intra-escrotal e uma lesão crônica de natureza luética ou tuberculosa o que se faz quer pelas reações sorológicas, quer pelo exame do aparelho gênito-urinário, pois que a tuberculose do epiclídimo frequentemente é secundária à tuberculose renal ou próstato-vesicular.

Hinman cita um caso pessoal de tumor do epidídimo que dava um quadro clínico de tuberçulose do epidídimo e.que apresentava, segundo relata o referido autor, "fístulas e áreas no escroto contraidas
e cicatrizadlas".

Mais dificil seria a confusão com as hérnias. 
O diagnóstico diferencial é menos facil com as hematoceles, pois nem sempre está indicada uma punção, como tambem, muitas vezes a anamnese nada esclarece.

A reação de Ascheim-Zondek vai nos orientar no estabelecimento do diagnóstico de certas neoplasias do testículo, como tambem nos informa acerca da malignidade das mesmas.

Segundo Henline existe uma relação entre a positividade da reação de Aschein-Zondek e a malignidade do tumor do testículo, pois se comportam ambas de acordo com uma escala decrescente no córion-epitelioma, no adenocarcinoma embrionário, no sarcoma, no seminoma e no teratoma.

Via de regra é dificil o diagnóstico dos tumores dos epidídimos: antes da operação ou autópsia. Eles não apresentam quadros característicos, diz HiNMAN.

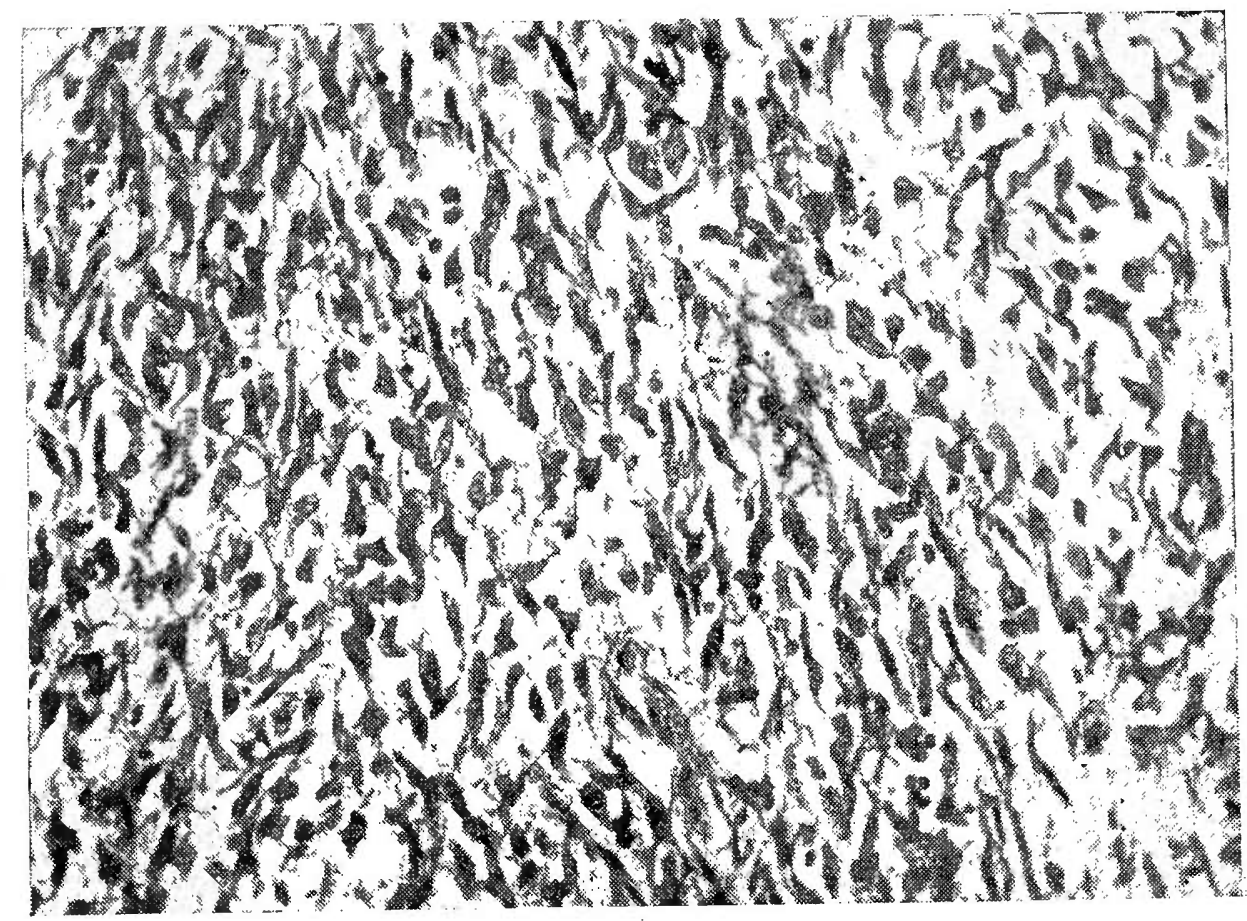

Fİ̀. V

Sarcoma parvi-fuso-celular do epidídimo.

(Prof. Carmo Lordy).

Segundo êsse mesmo autor a suspeita de tumor impõe umà ope-ração imediata, a qual não deve se limitar a uma simples exploração, com extirpação de um fragmento para biópsia, pois ạlem de deixar dúvidas diagnósticas, tal excisão poderia disseminar células tumorais ou bacilos tuberculosos.

A orientação aconselhada é a epididimectomia radical, associada. à radioterapia, que estabelecerá definitivaniente o diagnóstico. Caso existir comprometimento do testículo estará indicada a castração. 


\section{SUMMARY}

The AA. report the clinical and histopathological data from a case of sarcoma of the epididymus. It was a young man 16 years old that since five months presented a tumor in the right inguinoescrotal region. In the four initial months he only observed the augmentations in size, and in the last month it appeared a slight painful sensation in the region of the tumor, and only on the sudden and intensive moviments.

The AA. made the surgical ressection of the tumorous mass in a whole mass together with the testicle and the distal part of the ductus espermaticus. The surgical impression was of a neoplastic process of the epididymus, and the histopatological was of a sarcoma of spindle cells of the epididymus (Prof. Carmo Lordy). The AA. insist on deep radiotherapic applications, but, in spite of every care, three months later a roentgeen picture of the lungs revealed a pulmonar metastasis.

The AA., studying his case, made also some comments about:

a) classifications of the tumors of the epididymus;

b) its incidence;

c) its symptomatology, diagnostics and therapeutics.

In analysing the medical index of São Paulo (9.750 reports on biopsies and 13.400 reports of necropsic data) the AA. can state that this case is the first one reported in São Paulo, and, very probably, the first one published in Brazil.

\section{Preparad os F a r m a cê ut i c o s}

Temos a venda Marcas e Formulas licenciadas e incumbimo-nos de sua compra, venda, ou registro. LICENCIAMOS FORMULAS, PODENDO SER EXAMINADAS POR NOSSO TECNICO FARMACEUTICO OU FORNECER FORMULAS. Legalizamos Laboratorios Farmaceuticoș, fazemos quaisquer contratos, de instalação, de exploração, de propaganda, de fabricação.

C ON S U L T E - N O S SEM C O M R OMI S O

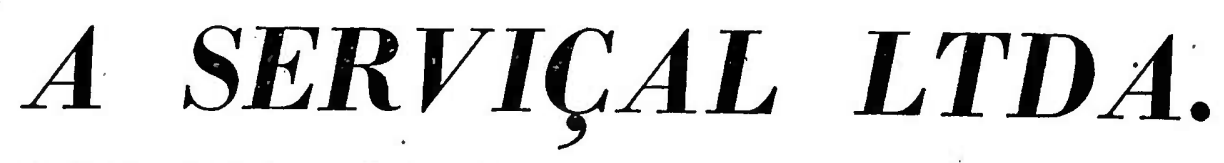

\section{AgENCIAS REUNIDAS RIO DE JANEIRO E S. PAULO}

\section{Diretor Geral: ROMEU RODRIGUES}

Marcas - Patentes e Licenças de Preparados Farmacêulicos - Comestiveis - Bebidas - Erc.

RIO DE J A N EIRO

Rua da Quitanda, 7.Sob.

(Perto da Rua S. Jobé)

CaIXa postal, 3384
Nosso lema: Servir, sem nos servir, dos clientes
$\begin{array}{llllllll}\mathbf{S} & \tilde{\mathbf{A}} & \mathbf{O} & \mathbf{P} & \mathbf{A} & \mathbf{U} & \mathbf{L} & \mathbf{O}\end{array}$

Rua Direita, 64 - 3.॰ And.

CAIXAS POSTAIS

3631 e 1421 